\title{
Primary Physical Education Teacher Identity
}

\section{Introduction}

Teacher identity has emerged as a separate research area in the last few decades and draws from both the social sciences and philosophical sciences. Identity is not a new concept in teacher education nor is the development of identity. The complexity and multiplicity of teacher identity is an important factor to consider when addressing teacher attrition. There are increasing concerns about teacher self-image and public perception of the role, and we are experiencing an increasing rate of teachers leaving the profession. Increasingly, the need for early career teachers to develop a strong sense of identity has been mooted as important for their well-being. Similarly, teachers' professional identity is a key factor in motivation and effectiveness and in turn retention. By developing their professional identity, teachers are able to give due consideration to their epistemological beliefs, educational philosophies, reflection, and sense of self (Friesen and Besley 2013).

Identity is a challenging concept that has numerous definitions and facets, and research has yet to provide a universally accepted definition. This raises a number of issues when trying to identify the important factors that comprise identity, suggesting that identity and identification are different and consideration of the product (identity) as well as the process (identification) is important. The dynamic nature of identity suggests that it is a fluid concept that incorporates the defining characteristics a person currently has, has had in the past, and what indeed they may be like in the future. It is accepted that identity is a prime influence on motivation and self- efficacy.

Identity is also understood as a relational phenomenon rather than a fixed attribute of a person. The fluid and relational aspects of identity raise many complex issues, but, despite its ranging definitions, Akkerman and Meijer (2011) identify three common themes: the multiplicity of identity, the discontinuity of identity, and the social nature of identity. This characterizes identity not as a fixed and stable entity but rather shifting with time and context and interactions. They advocate a dialogic approach to identity and offer explanations of how identity can be "both unitary and multiple, both continuous and discontinuous, and both individual and social" (p.309).

\section{Identity, Teaching and Primary Physical Education}

The lack of a consensus regarding what identity means makes this a complex phenomenon to study. The conflicting facets of identity reflect postmodernist views in that identity is viewed as fragmented and reflective of the multiple social contexts in which individuals find themselves, accepting the fluid and changeable nature of identity in the life course. Identities are formed through exposure to experiences, influenced by attitude and perceptions and impacted by the notions of gender, race, class, and sexuality. It is important to consider identities as inextricably linked to pedagogical practices and attitude and that individuals will align to sub identities differently depending on the context they are in.

Identity formation begins in early childhood and continues into adolescence where identity development is an important part of this phase (Friesen and Besley 2013). This involves experimenting with a range of identities and exploring and searching for meaning and sense of self. Importantly, it has been noted that identity formation is not unique to adolescence and can extend through adulthood and be revisited numerous times. The values of significant others in an individual's life hold much influence over identity development and place a substantial responsibility on the parents, carers, and educationalists in a child's upbringing. These various individuals are commonly understood as having a responsibility to provide opportunities for a child to develop their identity via exposure to a wide range of 
social, intellectual, and moral situations. Life events can help in constructing and redefining priorities, both personally and socially, serving as a way of reflecting upon identity. From a sociocultural perspective, becoming a teacher means developing a professional identity. Capel (2007) suggests that the decision to teach physical education is influenced by sporting success, positive physical education experiences, and effective relationships with significant others involved in this experience, such as coaches and teachers. Her research identified that people are more likely to become a teacher because of their success in sport rather than physical education.

Primary physical education teachers construct their understandings surrounding the subject through their personal experiences and the "historical, social and cultural construct in which physical education takes place" (Chroinin and Coulter 2012, p. 223). Primary physical education teachers' prior experience of physical education teachers not only affects their subject knowledge content but their efficacy in teaching certain disciplines within the subject, founded upon their personal experiences in physical education and sport. The implications of this are that the beliefs held by many primary physical education teachers are conservative and based on a sporting discourse; as a consequence, primary physical education has traditionally been organized into a multi-activity curriculum where the development of skills is prominent. Teachers employ a limited range of teaching styles, pre- dominantly "formal, didactic and teacher centred" (Capel 2007, p. 493), that serve to reinforce (intentionally or unintentionally) the physical education is sport pedagogy.

When considering the appropriate attributes of a physical education teacher, it would be careless to focus upon the ability to perform, play, and compete as this immediately causes self-doubt, apathy, and insecurities for teachers that do not possess or aspire to possess those qualities. In the case of many physical education teachers, this includes an exposure to a sporting discourse which is associated with elitism, winning, and superior physical skills. There are also factors involved in this discourse relating to racism, gen- der stigma, and classism, which are historically prevalent in sport. For example, assumptions made about black athletes as sprinters and women's long-standing struggle to access the same sports as men, as well as certain sports being perceived as reserved for the upper classes. Identity development is intrinsically linked to one's perception of self and how individuals interpret their sporting experiences, ability, and privileges afforded in their lives. Equally, individual perceptions of physical education are also influenced by several factors beyond education; sporting pursuit, spectatorship, government drivers, and policy all impact upon how physical education is understood, its purposes, and how it is taught.

When teachers enter the profession, they bring with them their own constructions of teaching and learning that have been formed based on their personal biographies, prior experience, personal characteristics, norms, and values. Pre-service teachers need to undergo a shift from non- teacher to teacher where they must consider their beliefs about what teaching is, its purpose aims and content. This is compounded by the complex nature of the modern school environment, the challenging nature of the school context, and the unique nature of physical education as a subject. Often primary teachers will define themselves as "sporty" or "non-sporty," and those that aligned closely with the "sporty" description felt that they would be more successful in teaching physical education. Identity emerges over time but also in correlation with interactions with others; in this situation a teacher may present themselves as a particular kind of person, with their values and beliefs, to other members of staff, and it is the response and affirmation from more experienced staff that can ascribe or withhold ascription or cause change to an identity. Therefore, new teachers can experience conflict between their preconceptions of teachers and teaching, for example, the training given in initial teacher education (which may be aligned with a student-centered and constructivist 
approach) and the experience of physical education schools (often more traditional, didactic, and sport oriented). There may be contradictions and tensions between these aspects in terms of negotiating, resolving, and understanding the complex factors at play of how to be successful in that context. Where an individual fails to conform to the expected identity of a physical education teacher, conflict can occur. For instance, in physical education, aspiring to be being a male dancer can raise tensions between social role identity and their socially defined group identity. Multiple identities (Friesen and Besley 2013) experienced at one time might prove to be contradictory or incompatible at times. In facing this conflict, teachers may find themselves making choices as to accepting or rejecting possibilities in professional, moral, technical, or social senses when they are making distinctions and choosing affiliations.

Sports participation and physical activity preferences strongly influence pre-service primary teachers' identity development and practices. Competing schema include the conceptions of sport and physical education. The experiences of primary physical education teachers may be so aligned to the sporting discourse that they are unable or unwilling to engage with alternative pedagogies and that preconceptions of health dis- courses and sporting discourses in pre-service physical education teachers can "overshadow the core messages of physical education in a primary context" (Chroinin and Coulter 2012, p. 223; Carse et al. 2018) and place them in a "mental straightjacket" where primary teacher trainees feel disempowered in their perceived future as a physical educator. These requirements may present issues regarding expectations placed upon primary physical education to be able know what to prioritize when the above approaches have conflicting philosophies (Carse et al. 2018). Primary teacher education offers numerous opportunities to refine their professional identity during training. The interactions with other teachers and staff are incredibly important in beginning to understand the roles and responsibilities of a primary physical education teacher (Carse et al. 2018), assuming that these experiences do not serve to reproduce stereotypical, conservative, and traditional approaches to teaching (Capel 2007).

Although the influences on pre-service teachers are well recognized, it is not clear how these beliefs evolve over time (Capel 2007). Phys- ical education practice is ingrained with traditional hegemonic identities, and there is a growing need for non-traditional identities to be acknowledged in the physical education fraternity (Carse et al. 2018). Historically, there has been an accepted "look" for physical education teachers and that these corporeal characteristics act as (social) capital in the physical education community and it is important to "look the part." Traditionally views about how a physical education teacher should look have included qualities associated with how their bodies should move and look. Conflict may be experienced if primary physical education teachers do not fit into the predefined "look" of a physical education teacher or indeed the social norms of what is acceptable. It is a common notion that physical education teachers may have a common vision of physical education and accept the socially constructed version of primary physical education teaching (Capel 2007). However, in a primary school set- ting, this is not always the case and can lead to teachers' feelings of isolation and not "fitting in," of being the "physical education teacher," in a derogatory sense and often in the minority of primary teachers able or confident enough to teach primary physical education.

In the case of primary physical education teachers entering the profession in England, the training given and the experiences had in school placements have been of limited success and there are significant challenges for trainees when mentors favor traditional content led approaches to teaching. Initial teacher education across England and the rest of the world is inconsistent in preparing teachers for the demands of the role of a physical education 
teacher (Carse et al. 2018) with variations in respect to content, emphasis, skills, and dispositions. A recognized curriculum for initial teacher education primary physical education could contribute to a more consistent and methodical approach to physical education teacher education.

For many years, the drive outside the physical education fraternity has been to devalue the subject and perceive physical education as merely recreation and a chance to "blow off steam" (Capel 2007). Historically, this has contributed to the marginalization of physical education as a low status subject. Physical education learning and teaching experiences are unique as they can- not easily be separated and offer both social, affective, cognitive, and physical opportunities.

There is an increasing body of evidence that physical education is a powerful tool for wholeschool improvement and raising attainment (Capel 2007). Generally, primary teachers enter the profession understanding the purpose of physical education to be skill development; other key beliefs among primary physical education teachers concerning the purpose of physical education include social development, healthism, physical activity, and fitness. Healthism dis- courses have transformed in recent years to reflect changes in the health needs of young people, obesity, and overweightness. Health discourses have continued to inform physical education con- tent and attitude, and primary physical education teachers should reflect on the role that primary physical education has in getting young people active.

Given the current national drive in the United Kingdom for health-enhancing physical activities, there is some debate as to whether prioritizing health as a purpose for primary physical education represents a shift in belief in recent years. It is problematic to assume that being physically educated equates to being physically active and vice versa. This raises the question as to whether primary physical education teachers have considered their values and beliefs as they pertain to primary physical education to empower them to innovate, create change and whether they are clear in their role in this journey. The health drive focusses largely upon physical activity and therefore separates the body and the mind. However, one can be physically healthy without being physically educated, and this calls into question the role of the primary physical education and, consequently, challenges primary physical education teachers to question their beliefs about the role and purpose of physical education.

Currently, in England, primary physical education teachers find themselves in a complex position of teaching a marginalized foundation subject that has had more funding in the last 5 years than all the other primary subjects combined. The physical education and school sport premium is part of the Olympic legacy funding that succeeded the London 2012 Olympics. It is provided for primary schools to spend as they see fit, with a focus on improving provision in physical education and school sport and, since 2018, well-being. It was designed to be spent on physical education and school sport and paid directly to primary schools. The impact of this funding upon identity is complex, and increasingly the role of a primary physical education teacher is less about teaching and more about the increasingly complex budgetary requirements and managing a team of individuals drawn from the wider workforce. There is a climate where there is a lack of opportunity to teach physical education, observe experienced teachers, and see good practice relating to planning, teaching, and assessment in the subject which is accompanied by apathy, reluctance, and avoidance from the existing teaching staff. 
Primary teacher education that includes physical education should ensure that teachers exit their training and embark on a career with a clear understanding of the purposes of primary physical education. Physical education teacher education can enable pre-service teachers to "filter" the potential conflicting discourses of physical education, sport, and health (Chroinin and Coulter 2012; Carse et al. 2018) and to recognize that learning is not only the development of skills; it is development of the person. However, many new entrants to the profession feel unable to challenge, innovate, and use the strategies they experience in initial teacher education. Indeed, many teachers read, interpret, and adapt the curriculum to match their own beliefs. This allows physical education teachers to teach what they have always done in the way they have always done it. It is easy to see why primary physical education teachers may experience conflict between what they value and believe, have been previously experienced (Capel 2007), are taught during initial teacher education and ultimately end up teaching.

\section{Cross-References}

Identity Learning in Teacher Education (http://link.springer.com/search?facet-eisbn=978981-13-1179-6\&facet-contenttype=ReferenceWorkEntry\&query=Identity\%20Learning\%20in\%20Teacher\%20Education)

Mentoring and Coaching in Primary Physical Education Initial Teacher Education (http://link.springer.com/search?facet-eisbn=978-981-13-1179-6\&facet-contenttype=ReferenceWorkEntry\&query=Mentoring\%20and\%20Coaching\%20in\%20Primary\%20P hysical\%20Education\%20Initial\%20Teacher\%20Education)

Research on Occupational Socialization in Sport Pedagogy, Lessons Learnt (http://link.springer.com/search?facet-eisbn=978-981-13-1179-6\&facet-contenttype=ReferenceWorkEntry\&query=Research\%20on\%200ccupational\%20Socialization $\% 20 \mathrm{i}$ n\%20Sport\%20Pedagogy\%2C\%20Lessons\%20Learnt)

Role of Workplace Learning in Teacher Education (http://link.springer.com/search?faceteisbn=978-981-13-1179-6\&facet-content-

type=ReferenceWorkEntry\&query=Role\%20of\%20Workplace\%20Learning\%20in\%20Teach er\%20Education)

\section{References}

Akkerman, S., \& Meijer, P. (2011). A dialogical approach to conceptualising teacher identity. Teaching and Teacher Education, 27, 308-319.

Capel, S. (2007). Moving beyond physical education sub- ject knowledge to develop knowledgeable teachers of the subject. The Curriculum Journal, 18(4), 493-507. Carse, N., Jess, M., \& Keay, J. (2018). Primary physical education: Shifting perspectives to move forwards.

European Physical Education Review, 24(4), 487-502. Chroinin, D., \& Coulter, M. (2012). The impact of initial teacher education on understandings of physical edu- cation: Asking the right question. European Physical 
Education Review, 18(2), 220-238.

Friesen, D., \& Besley, S. (2013). Teacher identity development in the first year of teacher education: A developmental and social psychological perspective. Teaching and Teacher Education, 36, 23-32. 